\title{
Biomass Production in Agroforestry Systems: V.E.Ri.For Project
}

\author{
Andrea R. Proto ${ }^{1, a}$, Giuseppe Zimbalatti ${ }^{1, b}$, Lorenzo Abenavoli ${ }^{1, c}$, \\ Bruno Bernardi ${ }^{1, d}$ and Soraya Benalia ${ }^{1, e}$ \\ ${ }^{1}$ Mediterranea University of Reggio Calabria, Department of Agriculture, Feo di Vito, 89122 - Reggio \\ Calabria, Italy

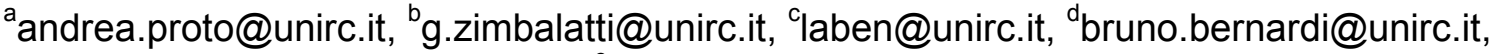 \\ esbenalia@unirc.it
}

Keywords: Biomass, Renewable Energy, Agroforestry Systems.

\begin{abstract}
The biomass for energy purposes, coming from agroforestry systems and timber industry, can provide various environmental and socio-economic benefits. Among all renewable energy sources, agroforestry biomass represents both an important alternative source to fossil fuels and an opportunity for the socio-economic development of various marginal areas in Italy. In particular, agroforestry is a collective name of land use systems in which woody perennials are grown in association with herbaceous plants and/or livestock in a spatial arrangements, a rotation, or both in which there are both ecological and economic interactions between the tree and the non-tree components of the system. Estimating availability of biomass resources is important to assess bioenergy production potential and so bioenergy contribution to annual energy demand. In the supply of biomass to energy use, the planning of operations is the basis for sustainable development of agroforest system. Most existing forest practice rules and recommendations did not anticipate this increased extraction of woody biomass and offer no specific guidance on how much removal is healthy for ecosystems. Intensification of biomass utilization, particularly for energy and fuel needs, presents a range of potential environmental risks. Therefore, the research focuses on development of guidelines for increasing a sustainable biomass supply chain at local scale, in order to facilitate energy planning that considers the local system carrying capacity and the potential of substitution of fossil fuels.
\end{abstract}

\section{Introduction}

In the last years public and scientific debate about the reduction of $\mathrm{CO} 2$ and polluting emissions has intensified and the importance of renewable energies and fuel has increased. Scientific researches on the economic possibility to use wood and biomass to obtain electric and thermal energy has shown contrasting results. In the last ten years in Italy several companies of the bio energy industry, attracted by generous Government subsidies planned to build dedicated power that use biomass as their main fuel [1]. The biomass for energy purposes, coming from farms, forestry, timber industry and Short Rotation Forestry (SRF) for energy, can provide various environmental and socio-economic benefits [2]. First of all, the production of forest biomass for energy involves the reduction of $\mathrm{CO} 2$ emissions $[3,4]$ and the improvement of forest functions, such as hydrogeological and biodiversity conservation. Moreover, forest biomass consumption could contribute to the socio-economic development of rural areas [5], through the restoration of agro-forest activities and technological advances in the bio-energy field.

Interest in woody biomass has increased because of rising fossil fuel costs, concerns about greenhouse gas emissions from fossil fuels, and the threat of catastrophic wildfires. However, getting woody biomass from the agroforestry system to the consumer presents economic and logistical challenges. Woody biomass is the lowest-value material removed from the land, usually logging slash, small-diameter trees, tops, limbs, or trees that cannot be sold as timber. The economics of biomass removal are challenging. 
The case studies demonstrate that biomass removal projects are rarely a source of income. In most cases, harvesting and transporting woody biomass is relatively costly because smaller stems have low value by volume and high handling costs, and most forest harvesting systems were originally designed for larger-diameter timber. However, some managers generated a profit by combining multiple forest products in the removal, taking advantage of fluctuations in the biomass market, and selling to established outlets [6].

Most existing forest practice rules and recommendations did not anticipate this increased extraction of woody biomass and offer no specific guidance on how much removal is healthy for ecosystems. Intensification of biomass utilization, particularly for energy and fuel needs, presents a range of potential environmental risks [7]. In fact, good biomass harvesting practices can enhance and improve agroforest land; poor practices can damage and devalue it. In Calabria the lack of an efficient and cost-effective supply chain system (harvesting, transportation, and delivery of biomass resources) restricts the sustainable Development of small scale wood-energy chain. If each step of bioenergy chain is not optimised the final cost of produced energy may not result to be competitive in comparison with energy from traditional fossil fuel. Therefore, the research focuses on development of guidelines for increasing a sustainable biomass supply chain at local scale, in order to facilitate energy planning that considers the local system carrying capacity and the potential of substitution of fossil fuels.

\section{Material and Methods}

In South Italy the use of wood for heating in the last ten years was promoted with European structural funds, rural development plans, energy projects, regional and provincial funds. In such a context, it is important the implementation of a small scale forest-wood-energy chain using local raw material and carrying out conversion phases in loco. The production of forest biomass for energy is assuming particular importance in Calabria for the forest vocation of its territory. The aim of this study is to allow biomass management for energy supply at a regional level. In fact, "V.E.Ri.For" is a regional project funded by PSR Calabria 2007- 2013 (Calabria's Rural Development Programme) under Project Action 124: "Cooperation for development of new products, processes and technologies in the agriculture and food sector and the forestry sector."

This project set up a partnership between forest holdings, consortia, cooperatives, IGEA Institute and Department of Agriculture in the Calabria region to improve the economic output of local biomass and support sustainable agroforestry management. The general objective of the project is to develop the local biomass supply-chain with the cooperation between different actors and innovation to produce renewable energy from biomass and to introduce sustainable practices and preserving biodiversity. Another important aspect of the project is rationalise management costs.

In detail, the project is structured according to these specific three several objectives:

- Biomass resource assessment: A fundamental condition for the development of such chain and for the use of biomass for energy purposes is knowing the quali-quantitative characteristics and the potentialities of forest lands. This phase estimates the potential production of biomass in the province of Reggio Calabria, where, recently, local authorities have shown a growing interest in forest biomass production (Fig. 1).

- Level of Mechanization adopted: In order to estimate the potentialities of biomass present in the province of Reggio Calabria and their susceptibility to mechanization from the point view of supply chain, a study has been carried out taking in consideration the productions and the number of the operating firms, with particular attention to their working systems and the mechanization levels they have achieved.

- Estimating Cost: An important aspect of any economic evaluation is the calculation of final energy costs, thereby including investment and related expenses for plant operating. The method study was based on stop-watch study in according to Berti [8]. In order to calculate the 
hourly cost of chipping operations at yarding as for the chipping at plant, Miyata approach was applied [9].
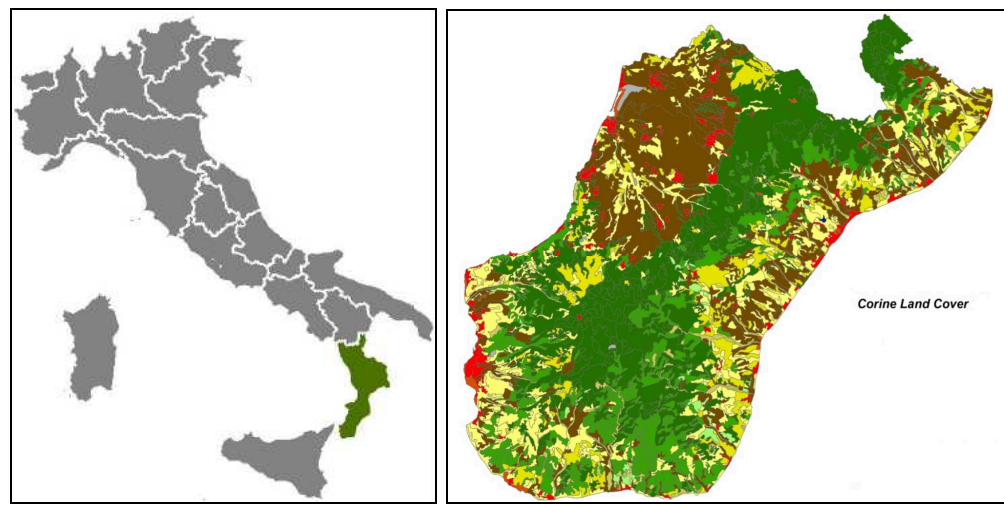

Figure 1: Geographical position of Calabria and the Province of Reggio Calabria

\section{Results}

The goal of a biomass resource assessment and of a supply chain is to promote the cost-effective, sustainable use of biomass energy. Biomass resource assessment consist to estimate the quantity of material necessary, taking into account technical and environmental constraints, and evaluate the quantity of material that could be recovered and made "available" for biomass energy uses. In order to assess the potential availability of woody biomass coming from forest resources, both the residual wood obtained from primary conversion in forests and the assortment percentages retrievable from utilization and destined for energy uses have been taken into account. In the first case, residual wood has been obsesses by applying an aliquot - expressed in percentage terms - to the potentially utilizable mass in every hectare of woodland.The results concerning the estimation of the total amounts of biomass potentially available every year from the forests belonging to the Province of Reggio Calabria are reported in Table 1. In particular, the volume of biomass that can be obtained from forests is estimated at 15415 (w $40 \%$ ) tons year $^{-1}$. To see increased the production of forest biomass, therefore, will be necessary to intervene on the recovery of abandoned areas with the reforestation of appropriate trees. Besides it will always need to watch over, so that an excessive demand of biomass doesn't push the wooded enterprise to convert the destination of final use of the woody products in biomass, dispersing so the real value of the woody assortments primary.

Table 1. Annual biomass in Province of Reggio Calabria

\begin{tabular}{|c|c|c|c|}
\hline $\begin{array}{c}\text { Main woodland crops in } \\
\text { Province }\end{array}$ & $\begin{array}{c}\text { Fresh } \\
\text { Biomass } \\
\left(\mathbf{m}^{\mathbf{3}} / \mathbf{h a}\right)\end{array}$ & $\begin{array}{c}\text { Fresh } \\
\text { Biomass } \\
\text { (tons/year) }\end{array}$ & $\begin{array}{c}\text { Biomass } \\
\mathbf{w} \mathbf{4 0 \%} \\
\text { (tons/year) }\end{array}$ \\
\hline Holm oak & 0.33 & 2406.6 & 1444 \\
\hline Pubescent hoak, Turkey hoak & 0.38 & 1962.5 & 1177.5 \\
\hline Beech & 0.57 & 5109.7 & 3065.8 \\
\hline Chestnut & 0.46 & 2962.5 & 1777.5 \\
\hline Exotic broadleaved & 4.12 & 10931.2 & 6558.7 \\
\hline Corsican Pine & 1.29 & 76.6 & 46 \\
\hline Silver fir & 1.3 & 266.5 & 159.9 \\
\hline Mediterranean Pines & 0.98 & 282.5 & 169.5 \\
\hline Exotic conifers & 2.19 & 1293.0 & 775.8 \\
\hline Forests of beech and silver fir & 1.12 & 254.0 & 152.4 \\
\hline Forests of beech and corsican pine & 0.98 & 67.0 & 40.2 \\
\hline Total & & $\mathbf{2 5 6 4 9}$ & $\mathbf{1 5 4 1 5}$ \\
\hline
\end{tabular}


The supply biomass chain is constituted by a sequence of activity that from biomass resource lead to energy conversion. This activity are harvesting, transportation, storage and energy conversion. The study of the level of mechanization adopted from forest enterprise highlights that the individual firm is the main management form, even if cooperative and associative societies are rather spread. As concern the type of carried out work, $12 \%$ of forest companies effect the felling, the setting up and the extraction of the timber; $88 \%$, instead, also effects the carriage, completing the productive cycle from the plant felling to the timber carriage towards the processing facilities or the direct sale in the case of firewood (Fig. 2). Around 220 forest firms manage to guarantee, thanks to the above-mentioned diversity of woodlands, considerable woody assortment, fairly subdivided into work timber, firewood and biomass. The study of productions shows an increase of firewood use in comparison with a constant demand for work timber in the reference period. Many entrepreneurs have changed, in few years, utilization systems and methods bringing a new transformation process to their technological cycle, promoting: whole tree extraction and processing systems in landing, use of forwarder e chipping on the fall bed or on the edge of the road with autonomous chippers. In this study it has emerged that, the use of new working systems or new specialized machines, has been adopted in different times in different calabrian forest areas. In addition, inside the forest firms which have invested in new technologies, the replacement of out-of-date technologies with innovative ones has not been immediate; in fact for some time the new has coexisted with the old. In many equipments, for example, where forwarders or skidders operate, the concentration phase is often followed by yoke of oxen or single horses. Although the cable crane is very spread all over the calabrian district, its performance is not very exploited, according to recent studies, because of firms little experience [10]. This is the most evident characteristic of tradition that still today marks the calabrian forest sector: the achievement of an innovative technology does not undermine the obsolete one: the latter, sometimes, is kept as a support.
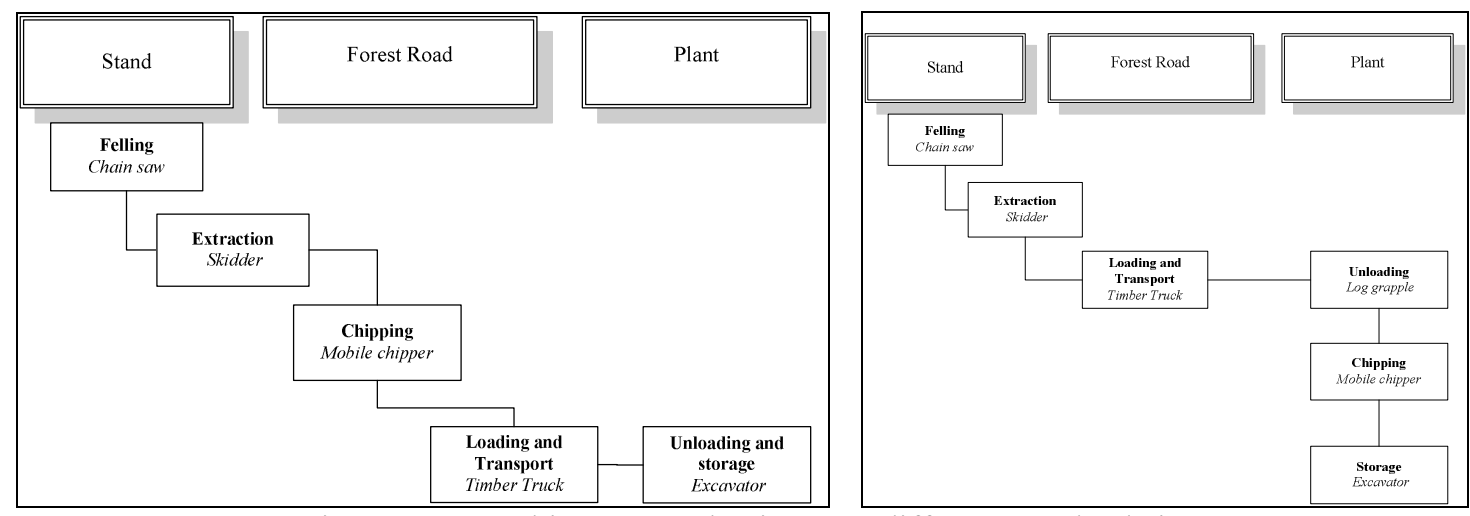

Figure 2. Forest biomass production: two different supply chain

The third object of this project (estimating cost phase) suggests that within a distance of $150 \mathrm{~km}$ from plant, the offer of forest energy wood is not enough. For what it concerns the supply cost, the supply chain with chipping operation at yarding result less cost-efficient in respect of the supply with chipping at energy plant (Fig. 3). The maximum cost-efficient supply distance, in fact, results $50 \mathrm{~km}$. When chipping is performed at energy plant and the supply considers roundwood, the cost-efficient supply distance increase also up to $160 \mathrm{~km}$. That depends on chipping cost: stationary chipping operation at energy plant presents generally a lower hourly cost and higher productivities. In the same time the supply chain shows an advantage when the transport concerns energy wood in form of roundwood in respect of wood chips. Anyway, the improvement of forest resource in province of Reggio Calabria cannot be attained only through a general increment in terms of biomass but should be rather based on a re-arrangement of the management of the same productive forest area likely to result in a steady productive supply of timber that responds to the needs of the wood chips market [11]. Factors that may lead to an higher cost are the low-density and non-homogeneous of biomass. 
The different surveys conducted during this project have a fairly critical about the development of a chain of biomass agro-forestry in the province of Reggio Calabria. In particular, the environmental and economic aspects are not always able to emerge with respect to their potential.
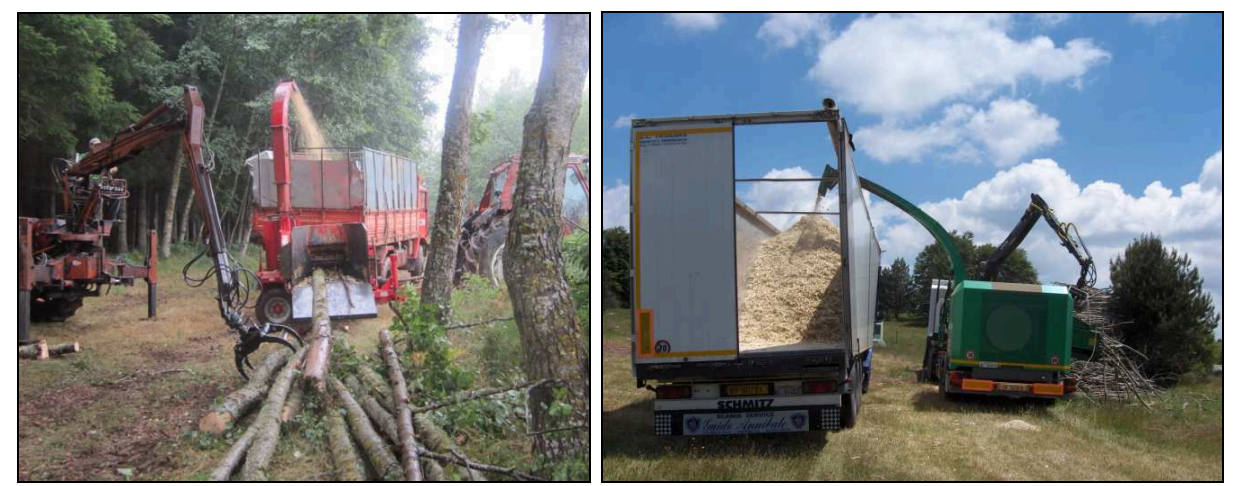

Figure 3. Biomass supply chain: different systems

\section{Discussion}

The case studies described in this paper show that all aspects of biomass supply chain are evolving. Markets are expanding as new uses are perfected and new energy plants are built. Technology is adapting to the requirements of small-diameter material. The role of biomass as a renewable source of energy is encouraging an increasing interest in environmental, social and economic issues. Thanks to this project many agroforest farms have diversified their forest production, starting in some cases also bio-energy production, and they have introduced more sustainable management practices, ensuring a better preservation of biodiversity.

Cooperation between institute of research, foresters, farms and the university was crucial to assess the needs for intervention. The network established among different actors along the supply chain helped to give new economic life to the biomass retrievable. The achieved results show how the area under investigation presents a good potential for an energetic enhancement of forest resources. Proper project planning and operations are needed to make sure these elements are part of any new supply chain and will help contribute to a successful biomass to energy project because an efficient and cost-effective supply chain allows to be competitive with other conventional fuels. However, the increase of biomass must be supports from a fit mechanization. The increase of productivity, both for the forest firms and for all the wood row companies, is due to a constant search of production efficiency, a proper selection of machinery and integration among the different sections of the row.

The acquisition of new means will allow the firms to operate also in those woodlands where the lack of roads and infrastructures, useful for the passing of the means, and the unevenness of the terrain lower the income of utilization operations.

\section{Acknowledgements}

This work was financially supported by the by PSR Calabria 2007- 2013 (Calabria's Rural Development Programme) under Project Action 124: "Cooperation for development of new products, processes and technologies in the agriculture and food sector and the forestry sector." 


\section{References}

[*] Equally the authors participated in all the phases of the present work

[1] F. Neri and F. Piegai: Biomass chipping operations: case studies in Tuscany. On proceeding of Meeting the needs of tomorrows' forests - New developments in forest engineering, On October 7th-11th. Boku, Wien (2007)

[2] F. Neri and G. Brunori: Bioenergia ed innovazione nelle aree rurali: il caso della mini-rete di teleriscaldamento a biomassa legnosa di origine forestale di Camporgiano, Atti del XLV Convegno SIDEA, Portici (2008)

[3] T. Nishizono, T. Iehara, H. Kuboyama and M. Fukuda: A forest biomass yield table based on an empirical model. Journal of Forest Research [10], (2005), Issue 3, pp. 211-220.

[4] B. Hellrigl: La Commissione Europea rivaluta le biomasse. Sherwood [124], (2006),pp. 33-38

[5] L. Ciccarese: Bio-energia e cambiamenti climatici. Sherwood [116], (2005), pp. 13-17

[6] B. Lattimore, C. T. Smith, B. D. Titus, I. Stupak, and G. Egnell: Environmental Factors in Woodfuel Production: Opportunities, Risks, and Criteria and Indicators for Sustainable Practices. In: Biomass and Bioenergy, 33(10):1321-1342, (2009)

[7] A. Evans: Synthesis of knowledge from woody biomass removal case studies. Santa Fe, NM: Forest Guild., (2009), p. 39

[8] S. Berti, S. Piegai and S. Verani: Manuale di istruzione per il rilievo dei tempi di lavoro e delle produttività nei lavori forestali. Quaderni d'Istituto di Assestamento e Tecnologia Forestale, Fascicolo IV. Firenze: Istituto di Assestamento Forestale. Faculty of Agriculture, University of Florence, (1989)

[9] E.S. Miyata: Determining fixed and operating costs of logging equipment. Forest Service General Technical Report, St. Paul, MN: North Central Experiment Station, (1980), USDA pp. $1-14$

[10] G. Zimbalatti, A. R. Proto: Cable logging opportunities for firewood in Calabrian forest. B. Engineering, 102, (2009), pp. 63-68. Information on http://dx.doi.org/10.1016/j. biosystemseng.2008.10.008

[11] R. Cavalli, G. Zimbalatti, S. Grigolato, A.R. Proto: Forest woodchips supply chain in Southern Italy. Proceeding of International Symposium on Forestry Mechanization, Schmallenberg, (2008), pp. 117-124 